\title{
PODER, TEMPO E HISTÓRIA: REFLEXÃO SOBRE A JUSTIÇA DE TRANSIÇÃO NO BRASIL.
}

\author{
Carlos Augusto de Oliveira Diniz ${ }^{1}$
}

\section{Resumo:}

O objeto do presente texto é a justiça de transição numa abordagem interdisciplinar com a história, sociologia e filosofia. Isso foi necessário porque o direito não consegue dar todas as respostas dada a complexidade do tema, sobretudo, no Brasil país de história bastante conturbada. A hipótese é a de que no Brasil a justiça de transição não tenha sido efetivada. $\mathrm{O}$ objetivo geral é estabelecer uma discussão interdisciplinar sobre a justiça de transição, o específico é analisar para compreender como a justiça de transição no Brasil. O método utilizado foi o dedutivo e a metodologia foi de revisão bibliográfica.

Palavras-chave: Poder; Tempo; História; Estado de Exceção; Justiça de Transição.

\section{POWER, TIME AND HISTORY: REFLECTION ON JUSTICE OF TRANSITION IN BRAZIL.}

\begin{abstract}
The object of the present text is the transitional justice in an interdisciplinary approach with the history, sociology and philosophy. This was necessary because the law cannot give all the answers given the complexity of the subject, especially in Brazil, a country with a very troubled history. The hypothesis is that in Brazil transitional justice has not been enforced. The overall goal is to establish an interdisciplinary discussion on transitional justice, the specific is to analyze to understand how transitional justice in Brazil. The method used was deductive and the methodology was bibliographic review.
\end{abstract}

Keywords: Power; Time; History; State of Exception; Transition Justice.

\section{Introdução.}

O presente trabalho é fruto de projeto de pesquisa que se encontra em andamento, apesar disso algumas constatações parciais nos encorajaram a produzir o presente artigo. Inicialmente é importante ressaltar que o objeto do presente texto é a justiça de transição.

\footnotetext{
${ }^{1}$ Doutor em Direito pela Pontifícia Universidade Católica de São Paulo (PUC-SP), Área de Concentração: Efetividade do Direito na linha de pesquisa: Ética, Linguagem e Justiça. Professor da Carreira de Magistério Superior do Curso de Direito da Universidade Federal de Goiás (UFG) - Regional Jataí-GO. Coordena o Projeto de Pesquisa "Poder, Estado e Capitalismo: Impactos no Processo de Construção do Direito (PI03572-2019)". Lattes: http://lattes.cnpq.br/3127802813505867 - E-mail: carlosaugustodiniz@ hotmail.com; Endereço: Universidade Federal de Goiás - Regional Jataí (Campus Jatobá / Prédio do Curso de Direito / Gabinete 24). BR 364, Km 195, no 3800, CEP: 75801-615, Jataí-GO.
} 
Procurou-se realizar uma abordagem interdisciplinar em que se buscou apoio na história, sociologia e filosofia. Isso foi necessário porque o direito não consegue responder a todas as indagações que os processos políticos e sociais são capazes de apresentar. Essa situação potencializa-se quando se analisa a situação do Brasil, pois é um país que possui uma elevada complexidade em sua histórica.

Partimos da hipótese de que devido às peculiaridades históricas brasileiras a justiça de transição tenha enfrentado, ou ainda enfrenta, maior dificuldade para efetivar-se. E isto necessariamente está ligado a uma possibilidade que o direito possui e consequentemente possibilita a sociedade que é a possibilidade/capacidade de regressar ao passado (tal ideia é explicada no terceiro item do texto).

O objetivo geral é estabelecer uma discussão interdisciplinar sobre a justiça de transição procurando abordar todas as potencialidades que esse conceito possa proporcionar a sociedade. Já quanto ao objetivo específico o trabalho visa analisar para compreender como a justiça de transição se deu, se dá, ou se dará no Brasil ante as suas características especificas dessa sociedade brasileira.

Optamos pelo método dedutivo, pois partimos de questões universais como o conceito de poder, tempo e história para que pudéssemos chegar a um objeto mais específico que é a justiça de transição no contexto social, político e histórico brasileiro. E dessa forma optamos por uma metodologia fundada em revisão bibliográfica.

O desenvolvimento do texto foi estruturado em três itens necessários para a condução do raciocínio. Primeiramente analisamos o poder como e como a história possui a capacidade de armazená-lo sob a forma de fato histórico. Posteriormente foi necessário se debruçar sobre os conceitos e possibilidades do tempo e da história. Por fim analisamos como o direito possui a capacidade de regressar no tempo por intermédio da justiça de transição e como isso se localiza no caso Brasileiro.

\section{O Onde do Poder.}

Antes de iniciar a abordagem do elemento nuclear para o presente trabalho é necessário situá-lo na história. De inicio manifestamos a certa dificuldade para realizar tal tarefa, pois evidente que um historiador teria maiores e melhores elementos para fazê-lo, porém não podemos deixar de tentar. 
O elemento nuclear a que se refere é o poder. Sua abordagem mostra-se fundamental para o estabelecimento da base sobre a qual poderá discutir memória, verdade, justiça de transição, pois todos os três se relacionam com o poder. Assim, a ideia é descer até as ramificações do poder, para tanto, entendemos as seguintes escalas: $1^{\circ}$ ) Governo (Rei, Assembleia) » $2^{\circ}$ ) Estado (Leviatã) » $3^{\circ}$ ) Constituição » $4^{\circ}$ ) Poder Constituinte Originário » $5^{\circ}$ ) Sociedade (povo, população) » $6^{\circ}$ ) Indivíduo ${ }^{2}$.

Dessa forma, resta saber se o poder está com ou no indivíduo? É importante citar passagem da Constituição da República Federativa do Brasil no artigo $1^{\circ}$, Parágrafo único: Todo o poder emana do povo, que o exerce por meio de representantes eleitos ou diretamente, nos termos desta Constituição. Logo, a percepção é a de que o descer até as ramificações do poder gera a sensação de que se chega mais próximo de sua fonte e ao mesmo tempo tem-se uma sensação de movimento do concreto para o abstrato ${ }^{3}$.

Refletindo sobre o poder é compreender se ele possui um nascimento único, ou seja, se ele surgiu e desde então é o mesmo e neste caso mais próximo de um substantivo (objeto, instrumento), ou se o poder seria tão volátil que necessitasse de um nascimento constante e por isso mais próximo de um verbo (ação), e neste segundo caso talvez o processo de nascimento se faça mais importante que o próprio fruto gerado. ${ }^{4}$

Tal esclarecimento pode contribuir para saber se o poder está no ou com o indivíduo. O poder como verbo deve ser dividido em transitivo e intransitivo. Verbo transitivo é aquele que não se basta sozinho, ele precisa de um complemento para conseguir expressar o sentido; o verbo intransitivo será aquele que consegue esgotar o sentido sem precisar de outro verbo que possa complementá-lo.

Como verbo, seu uso mais intuitivo nos faz vê-lo sempre conectado a outros verbos. E assim não designa, modaliza: poder correr, gritar, sofrer, ser, pensar, morrer, viver. Essa transitividade, associada a outro verbo, modaliza como condição de ser, sem ser necessariamente (possibilidade): poder subir, poder saltar; ou modaliza como condição de agir sem obrigatoriedade de agir (faculdade): poder casar, poder negociar; ou modaliza como estar sujeito, suportar (passividade): poder errar; ou modaliza como ter chance (oportunidade): poder afinal, respirar; ou modaliza como controle, domínio (potência): poder dissimular; ou modaliza como autorizar, permitir (permissão): poder sair ou entrar; ou modaliza como induzir a uma ação

\footnotetext{
${ }^{2}$ DINIZ, 2016, p. 42.

${ }^{3}$ DINIZ, 2016.

${ }^{4}$ FERRAZ JUNIOR, 2009.
} 
(sugestão, recomendação, conselho): Pode me emprestar seu lápis? Ou modaliza como estar autorizado, ter um direito (direito subjetivo): poder usar, gozar ${ }^{5}$.

Nesta esteira quando o texto constitucional ao citar que o poder emana é possível perceber uma complementação entre ambos. O verbo emanar revela um fluir, ter origem em, vir, exalar, espalhar-se em pequenas partes, desprender-se, decorrer ou ter origem em algo, nascer ou resultar de. ${ }^{6}$

Segundo tal delineamento, o poder está no indivíduo e por isso possui um nascer constante, logo, não há que se falar em poder com o indivíduo, pois essa constatação dá a noção de que o poder seja um substantivo, ou seja, algo que possa ser objeto de propriedade.

\footnotetext{
Em seu uso transitivo, sua substantivação é um equívoco. Substantiva é, eventualmente, a ação que ele modaliza. Ser possível, ser permitida, ser facultada, ser capaz não são substantivações de poder nem devem ser tomados como substancias. Sequer se deve dizer que são modos de ser, mas apenas performações linguísticas. Ou seja, o uso transitivo do verbo poder, como modalizador, não me desvenda algo, alguma coisa (uma faculdade, uma possibilidade, uma autorização...um poder!). Não é mais que um modal: ser possível, ser autorizado, ser permitido, ser capaz etc. ${ }^{7}$
}

Portanto, o poder por estar no indivíduo que pode ser entendido como a fonte natural daquele. Logo, posteriormente a esse processo de raciocínio dedutivo (do Governo para o Indivíduo) surge uma indagação: seria possível armazenar, acumular o poder? Logo, concluise que o acúmulo é impossível, sobretudo, porque o poder em seu estado abstrato como verbo, não permite essa possibilidade.

Doutra forma, pensar se o poder possa ser acumulado em seu estado concreto de substantivo, assim entendido quando se apresenta na forma de resultado/efeito, produzido por uma relação. Insta frisar que quando se fala em acúmulo de poder em sua forma concreta isso se mostra possível pela História, ou seja, é no processo histórico que se percebe o acúmulo de poder.

Portanto, o poder é passível de uma mutação, pois pode sair da condição de verbo e passar para a condição de substantivo, ou seja, do abstrato para o concreto, o poder seria o verbo que quando produz efeito qualquer sobre o homem passa para a condição de substantivo, e agora estará armazenado na História e percebe-lo em sua forma concreta é um modo de visibilizá-lo.

\footnotetext{
${ }^{5}$ Ibidem. p. 3.

${ }^{6}$ DINIZ, 2016.

${ }^{7}$ FERRAZ JUNIOR, 2009. p. 3.
} 
E o fato de estar acumulado na História não significa que ele não possa continuar gerando efeitos, pois apesar de a História ser estruturada em fatos é como se ocorresse uma reformulação constante do poder concreto armazenado na História. Para exemplificar o que se diz pensemos no lixo radioativo que não deixa de irradiar após sua vida útil ${ }^{8}$.

O papel da História é importante pelo fato de apresentar-se como "armazenadora" do poder quando este se encontra em sua forma concreta, mas também e principalmente, porque é como se aquela característica de emanar poder que pertence ao povo/indivíduo também fosse assumida pelo poder, agora concreto na forma de fato armazenado na História. De modo que, o poder em fase/estado concreto não se esgota, não desaparece, ele continua a irradiar-se e produzir efeitos sobre o homem ${ }^{9}$.

\section{Tempo e História.}

Já pontuado que o poder em estado concreto/substantivo é armazenado na História como fato é de se ressaltar que o poder também se relaciona com o tempo, sendo este entendido como algo mais amplo que o conceito de História. Abordaremos brevemente o tempo de modo breve, pois sua complexidade não permite esgota-lo neste trabalho, porém, tal abordagem nos dará subsídios importantes. Logo, temos:

Podemos distinguir três concepções fundamentais: $1^{\mathrm{a}}$ o T. como ordem mensurável
do movimento; $2^{\mathrm{a}}$ o T. como movimento intuído; $3^{\mathrm{a}}$ o T. como estrutura de
possibilidades. À primeira concepção vinculam-se, na Antiguidade, o conceito
cíclico do mundo e da vida do homem (metempsicose) e, na época moderna, o
conceito científico de tempo. À segunda concepção vincula-se o conceito de
consciência, com a qual o T. é identificado. A terceira concepção, deriva da filosofia
existencialista, apresenta algumas inovações na análise do conceito de tempo. ${ }^{10}$

Dentre essas concepções destacamos a segunda concepção, pois o objeto do trabalho relaciona-se mais adequadamente com essa ideia de consciência com a qual o tempo é identificado. Salutar é o papel das reflexões de Santo Agostinho sobre essa capacidade de análise do tempo:

A S. Agostinho deve-se a melhor expressão e a difusão dessa doutrina na filosofia ocidental. O T. é identificado por Agostinho com a própria vida da alma que se estende para o passado ou para o futuro (extensio ou distensio animi.). S. Agostinho diz: "De que modo diminui e consuma-se o futuro que ainda não existe? E de que modo cresce o passado que já não é mais, senão porque na alma existem as três

\footnotetext{
${ }^{8}$ DINIZ, 2016, p. 61.

${ }^{9}$ DINIZ, 2016, p. 62.

${ }^{10}$ ABBAGNANO, 1998, p. 944.
} 
coisas, presente passado e futuro? A alma de fato espera, presta atenção e recorda, de tal modo que aquilo que ela espera passa, através daquilo que ela presta atenção, para aquilo que ela recorda. Ninguém nega que o futuro ainda não exista, mas na alma já existe a espera do futuro; ninguém nega que o passado já não exista, mas na alma ainda existe a memória do passado. E ninguém nega que o presente careça de duração porque logo incide no passado, mas dura a atenção por meio da qual aquilo que será passa, afasta-se em direção ao passado" (Conf., XI, 28,1)A tese fundamental dessa concepção de T. foi enunciada pelo próprio S. Agostinho: "A rigor, não existem três $\mathrm{T}$., passado, presente e futuro, mas somente três presentes: o presente do passado, o presente do presente e o presente do futuro" (Ibid., XI, 20, 1).

O modo de pensar de Santo Agostinho é intrigante devido a sua facilidade de compreensão, pois somente no presente é que se poderá refletir sobre o passado e o futuro, eis a sua genialidade, ou seja, análise do tempo só pode ocorrer no presente ele é o lugar/ponto em que ocorre o encontro entre passado e futuro.

Para contribuir com esse raciocínio vamos à obra de Stephen William Hawking, tratase do livro Uma breve História do Tempo ${ }^{12}$ é uma obra que também apresenta elementos importantes para podermos refletir sobre o tempo. Sendo assim, é necessário ressaltar que estudiosos promoveram alterações, ou abalos, na forma de compreensão do tempo.

O marco desse processo foi a teoria da relatividade de Albert Einstein responsável pela quebra a compreensão de um tempo absoluto, ou seja, com medida/mensuração igual para variados observadores. A teoria da relatividade comprovou a relação entre tempo e espaço de modo que poderíamos nos mover tanto no tempo quanto no espaço ao mesmo tempo, ou em apenas um deles, e isso possibilitou que o tempo é relativo e por isso varia conforme o observador/medidor.

Mas Stephen William Hawking pontua uma diferença entre as compreensões real e imaginária do tempo. Vejamos:

\begin{abstract}
Quando se tentou unificar a gravitação coma mecânica quântica, foi necessário introduzir a ideia de tempo "imaginário". O tempo imaginário é indistinguível das direções no espaço. Se podemos ir para o norte, podemos dar meia-volta e ir para o sul; da mesma forma, se podemos avançar no tempo imaginário, devemos ser capazes de nos virar e retroceder. Isso significa que não pode haver diferença importante entre ir para frente e para trás no tempo imaginário. Em contrapartida, quando se olha para o tempo "real", há uma grande diferença entre essas direções, como todo mundo sabe, De onde vem essa diferença entre passado e futuro? Por que nos lembramos do passado, mas não do futuro? ${ }^{13}$
\end{abstract}

\footnotetext{
${ }_{12}^{11}$ ABBAGNANO, 1998, p. 946.

${ }^{12}$ HAWKING, Stephen William. Uma breve história do tempo. Ilustração Ron Miller; Tradução Cássio de Arantes Leite. 1 ed. Rio de Janeiro: Intrínseca, 2015.

${ }^{13}$ Ibidem. p. 180.
} 
Entendemos que tais perguntas complementam o pensamento de Santo Agostinho sobre o presente do passado, presente do presente, e o presente do futuro ${ }^{14}$. Porém, Stephen William Hawking difere de Santo Agostinho na medida em que analisa o futuro não como uma projeção/idealização, mas entendemos que sua análise parte de que o futuro seria algo concreto, ou seja, já existente, porém não conseguimos vê-lo fora do presente. Porém, esse algo concreto é a desordem/entropia, ou seja, nada tem a ver com a falsa imagem de que o futuro já esta pronto, definido pelo destino.

Contudo, há uma grande diferença entre as direções para frente e para trás do tempo
real na vida comum. Imagine um copo d'água caindo de uma mesa e estilhaçando no
chão. Se você filma a cena, é fácil dizer se está indo para a frente ou para trás. Se
passa o filme para trás, vê os cacos saindo do chão e se juntando para formar um
copo inteiro sobre a mesa. Dá para perceber que o filme está voltando porque nunca
se observa esse tipo de comportamento no mundo normal. Se assim fosse, os
fabricantes de copos iriam à falência. Em geral, a explicação dada para o fato de não
vermos copos quebrados se juntando no chão e pulando de volta para a mesa é que
isso é proibido pela segunda lei da termodinâmica. Ela afirma que, em qualquer
sistema fechado, a desordem ou entropia sempre aumenta com o tempo. Em outras
palavras, é uma espécie de lei de Murphy: as coisas sempre tendem a dar errado!
Um copo intacto sobre a mesa é um estado de ordem elevada, mas um copo
quebrado no chão é um estado desordenado. É fácil ir do copo sobre a mesa no
passado para o copo quebrado no chão no futuro, mas não percorrer o caminho
inverso. O aumento da desordem ou entropia com o tempo é um exemplo do que
chamamos de seta do tempo, algo que distingue o passado do futuro, estabelecendo
uma direção. Existem pelo menos três setas do tempo distintas. Primeiro, há a seta
do tempo termodinâmica, a direção na qual a desordem ou entropia aumenta.
Depois, há a seta do tempo psicológica. Essa é a direção em que sentimos o tempo
passar, a direção em que nos lembramos do passado, mas não do futuro. Enfim, há a
seta do tempo cosmológica. Essa é a direção do tempo em que o universo está se
expandindo, em vez de se contrair. ${ }^{15}$

Estas ditas setas do tempo possuem uma interação que estabelece resultados práticos. Imagine, por exemplo, a seta do tempo psicológico que devido a sua relação com as demais produz no homem a sua capacidade de se lembrar do passado e nunca do futuro. Isto porque a seta psicológica é determinada pela seta termodinâmica e necessariamente apontam para o mesmo rumo ${ }^{16}$.

Pois bem, a atuação direta do homem não tem poder para modificar o rumo de pelos menos duas das setas descritas, a saber: seta do tempo termodinâmico e seta do tempo cosmológico, ou seja, a atuação humana não possui instrumentos capazes de impedir/conter/reverter a entropia ou caminho rumo a desordem, e no mesmo sentido não existe instrumento que permita ao homem impedir o processo de expansão do universo.

\footnotetext{
${ }^{14}$ ABBAGNANO, 1998, p. 946.

${ }^{15}$ HAWKING, 2015, p. 180/181.

${ }^{16}$ Ibidem.
} 
Por outro lado o homem tem instrumentos e condição para promover uma guinada no rumo do tempo psicológico. O instrumento que possibilita que o homem consiga mudar o rumo do tempo psicológico é o Direito.

O Direito como se sabe é uma criação, uma ideia, presente no mundo do dever ser, pois se a igualdade existisse não haveria necessidade de almeja-la nos textos legais, por exemplo. E é justamente esse seu caráter de ideia que permite ao Direito uma regressão ao passado, ou mudança do rumo da seta do tempo psicológico.

Logo, o homem pode voltar ao passado e poderá revivê-lo ou transformá-lo, pois o direito seja no passado, presente, ou futuro nada mais é que uma ideia/dever ser. Daí a capacidade psicológica, e, sobretudo filosófica, que o Direito dá ao homem.

Isso permite que se estabeleça um paralelo: O Direito é a estrada pavimentada por onde o poder deve se locomover. O poder pode andar por qualquer lugar (e isso representará o seu descontrole) o direito é a forma/dever ser/ideia que evita o descontrole do poder. $\mathrm{E}$ o descontrole do poder potencializa a entropia na definição de Stephen William Hawking, ou seja, acelera tal processo para a desordem.

Nesse raciocínio o homem possui a capacidade de regressar ao passado não para revivê-lo, mas para enquadrá-lo na forma direito e dessa maneira diminuir os riscos de entropia/desordem. Logicamente, estamos utilizado o texto de Stephen William Hawking para estruturarmos um pensamento filosófico nada pode ser tomado ao pé da letra, pois o objetivo é refletir sobre a relação direito no tempo e isso será necessário para a sequencia deste texto.

Porém, fazer essa regressão no tempo precisa necessariamente que se adentre dentro de outro conceito não menos importante que o tempo, trata-se da História. Anteriormente pontuamos que a História tem capacidade de armazenar poder por meio dos fatos, mas agora é importante trazer um conceito específico sobre a História para que as ideias possam estar mais claras.

Dessa forma, quando se analisa a história ${ }^{17}$ é preciso fazer o exercício de regressão no tempo e espaço do objeto/fato/poder sob pena de anacronismo como no caso do julgamento pelo Supremo Tribunal Federal da Arguição de Descumprimento de Preceito Fundamental 153 (ADPF 153). Aqui é importante pontuar que entendemos que exista uma simbiose entre

\footnotetext{
${ }^{17}$ Ressalta-se que é uma análise feita não por um historiador, mas alguém com formação jurídica. Logo, naturalmente passiveis de análise incompleta. Ademais, é uma análise de suporte teórico não se trata do objetivo do presente trabalho.
} 
tempo, espaço, e história. Poderíamos até refletir se a história não seria o tempo em dado espaço.

Dessa forma, inicialmente utilizaremos a compreensão de Jacques Le Goff presente em sua obra História e memória ${ }^{18}$. Neste sentido, o autor pondera que a história possui como elemento estruturante, material fundamental, o tempo e com destaque para a cronologia expressa pelo calendário.

O calendário revela o esforço realizado pelas sociedades humanas para domesticar o tempo natural, utilizar o movimento natural da lua ou do sol, do ciclo das estações, da alternância do dia e da noite. Porém, suas articulações mais eficazes - a hora e a semana - estão ligadas à cultura e não à natureza. O calendário é o produto e expressão da história: está ligado às origens míticas e religiosas da humanidade (festas), aos progressos tecnológicos e científicos (medida do tempo), à evolução econômica, social e cultural (tempo do trabalho e tempo de lazer). Ele manifesta o esforço das sociedades humanas para transformar o tempo cíclico da natureza e dos mitos, do eterno retomo, num tempo linear escandido por grupos de anos: lustro, olimpíadas, século, eras, etc. À história estão intimamente conectados dois progressos essenciais: a definição de pontos de partida cronológicos (fundação de Roma, era cristã, hégira e assim por diante) e a busca de uma periodização, $a$ criação de unidades iguais, mensuráveis, de tempo: dia de vinte e quatro horas, século, etc. Hoje, a aplicação à história dos dados da filosofia, da ciência, da experiência individual e coletiva tende a introduzir, junto destes quadros mensuráveis do tempo histórico, a noção de duração, de tempo vivido, de tempos múltiplos e relativos, de tempos subjetivos ou simbólicos. O tempo histórico encontra, num nível muito sofisticado, o velho tempo da memória, que atravessa a história e a alimenta. ${ }^{19}$

O tempo expresso pelo calendário é elemento importante para o conceito de tempo psicológico definido anteriormente no texto. Equivale a dizer que é o tempo cronológico que facilita a compreensão psicológica do tempo pelo homem. O calendário é um apoio porque estabelece uma linha virtual que ajuda a posicionar a memória, elemento central neste processo de refletir sobre o passado, presente, futuro.

Aqui é necessária uma clareza dos papeis do observador ${ }^{20}$ e do objeto, pois por vezes pode-se deparar com uma real confusão entre a história e o a idealização do historiador. Dessa forma, a história não trata nem do passado enquanto tal nem, das concepções do historiador enquanto tais, mas da inter-relação entre os dois aspectos ${ }^{21}$. E sobre essa concepção pontua o autor:

\footnotetext{
${ }^{18}$ LE GOFF, Jacques. História e memória / Jacques Le Goff; tradução Bernardo Leitão. [et al.]. Campinas: Editora da UNICAMP, 1990.

${ }^{19}$ LE GOFF, 1990. p. 12/13.

${ }^{20}$ Ressalte-se que para o raciocínio deste trabalho, apesar da formação em área diversa, também nos colocamos na posição de historiador/observador.

${ }^{21}$ LE GOFF, 1990. p. 24.
} 
Concepção simultaneamente fecunda e perigosa. Fecunda, porque é verdade que o historiador parte do presente para pôr questões ao passado. Perigosa, porque se o passado tem, apesar de tudo, uma existência na sua relação com o presente, é inútil acreditar num passado independente daquele que o historiador constrói. Esta consideração condena todas as concepções dum passado "ontológico" como é expresso, por exemplo, na definição de história de Émile Callot: "Uma narração inteligível de um passado definitivamente esgotado" [1962, p. 32]. O passado é uma construção e uma reinterpretação constante e tem um futuro que é parte integrante e significativa da história. ${ }^{22}$

Este processo não pode dar margem para que se cometa o anacronismo, ou seja, é uma tarefa que deve ser feita de modo meticuloso, cauteloso. Como já dissemos o regresso ao passado é uma possibilidade dada pelo direito, porém, para que isso seja profícuo deve partir com metodologia e conceitos bem definidos e principalmente a certeza de que o fato objeto de análise já esgotou seu processo, ou seja, se já entrou para a história ou se ainda está em amadurecimento/conclusão.

Saber se o fato histórico já se concluiu é fundamental para a sequência do presente trabalho, pois iremos abordar a Justiça de Transição no Brasil como o instrumento concreto que possibilita efetivamente que o direito regresse no tempo. Em especial iremos discutir focar nossa análise na ditadura militar.

\section{O Direito pode regressar no tempo: Justiça de Transição como instrumento.}

Até aqui construímos um raciocínio de que o direito por pertencer ao mundo do ser, e por isso das ideias, possui a capacidade de regressar no tempo. Pontuamos ainda que a História possui a capacidade de armazenar o poder em forma de fatos históricos que apesar de passados não estão estanques, mortos, eles permanecem vivos e de algum modo irradiando poder no tempo presente e consequentemente no futuro.

Feitas essas recapitulações é necessário demonstrar o modo pelo qual o direito permite essa volta ao passado. Dessa forma alguns pontos estruturam este tópico: Primeiro apresentaremos um conceito para justiça de transição. Posteriormente abordaremos a nossa situação histórica atual procurando nos situar no tempo e no espaço. Por último analisaremos se nesse exercício, possível graças a Justiça de Transição, a história deve ser julgada ou compreendida?

\footnotetext{
${ }^{22}$ Ibidem.
} 
Primeiramente citaremos duas notícias recentes para contribuir com a reflexão aqui proposta. A primeira notícia é a seguinte:

O sargento reformado Antonio Waneir Pinheiro de Lima, o "Camarão", virou réu nesta quarta (14), após o Tribunal Regional Federal da $2^{a}$ Região aceitar a denúncia do Ministério Público Federal, por crimes cometidos na ditadura militar. É a primeira vez que a segunda instância da Justiça brasileira entende que a Lei de Anistia não protege o crime de tortura. Camarão é acusado de sequestrar e torturar Inês Etienne Romeu, durante a ditadura militar. Os crimes ocorreram na Casa da Morte, em Petrópolis, na região serrana do Rio de Janeiro. A vítima, que faleceu em 2015, foi a única sobrevivente do centro de tortura e denunciou o caso. "Os magistrados consideraram, por maioria, que os crimes praticados são de lesahumanidade e, por isso, deve-se aplicar a Convenção Americana dos Direitos Humanos - que não permite a prescrição, nem a anistia dos crimes" [... $]^{23}$

Essa notícia é importante na medida em que trata-se de um órgão colegiado que é o Tribunal Regional Federal da $2^{\mathrm{a}}$ Região e sobretudo por dois outros aspectos, o primeiro se deve ao reconhecimento de que crimes contra a humanidade são imprescritíveis e impossíveis de serem anistiados, e em segundo lugar porque o Brasil atravessa um período obscuro e nebuloso de sua história em que o discursos e ações fascistas, tacanhas, retrógradas, têm lugar de destaque.

A outra notícia é referente a um caso da Alemanha, vejamos:

\begin{abstract}
Alemanha vai julgar ex-guarda nazista por 5.230 mortes. A Justiça alemã marcou para outubro o julgamento de um ex-membro da SS (organização paramilitar durante o regime nazista) de 92 anos por cumplicidade na morte de 5.230 prisioneiros no campo de concentração de Stutthof, no atual território da Polônia, afirmaram promotores. Esse deve ser um dos últimos julgamentos de crimes nazistas. Guarda no antigo campo de Stutthof, Bruno D. é acusado de envolvimento em assassinatos cometidos entre agosto de 1944 e abril de 1945, período em que atuou no local, que ficava perto da então cidade alemã de Danzig (hoje Gdansk). Segundo a porta-voz da Promotoria de Hamburgo, ele fez uma confissão parcial dos atos. Bruno integrou a máquina "de assassinatos em massa" no campo de concentração por meio de sua condição de guarda da SS, de acordo com a Promotoria, quando tinha entre 17 e 18 anos. Segundo o jornal Die Welt, da Alemanha, o réu reconheceu que atuou no campo de concentração e admitiu que viu pessoas sendo levadas para serem executadas em câmaras de gás. Ele argumentou, no entanto, que isso não significa que ele seja culpado. ${ }^{24}$
\end{abstract}

A Alemanha é um caso, não o único, emblemático de justiça de transição, pois foi palco de acontecimentos históricos de proporções assustadoras para a humanidade e

${ }^{23}$ JORNAL GGN. Pela $1^{\text {a }}$ vez, Justiça entende que tortura não prescreve e transforma agente da Ditadura em réu. Disponível em: <https://jornalggn.com.br/noticia/pela-1a-vez-justica-entende-que-tortura-naoprescreve-e-transforma-agente-da-ditadura-em-reu/>. Acesso em: 15 de AGO. 2019.

24 AGÊNCIA BRASIL. Alemanha vai julgar ex-guarda nazista por 5.230 mortes. Disponível em: <https:/www.msn.com/pt-br/noticias/mundo/alemanha-vai-julgar-ex-guarda-nazista-por-5230-mortes/ar-

AAFK9Bh?li=AAggXC1\&ocid=mailsignout>. Acesso em: 14 de AGO. 2019. 
consequentemente procurou regressar ao seu passado para efetivamente realizar a transição de seu período autoritário para um de respeito ao ser humano, ou democrático.

Nesta linha cite-se o trabalho desempenhado por frações do Ministério Público Federal que atuam seja na persecução criminal daqueles que cometeram crimes contra a humanidade, seja na manutenção de acervo histórico ${ }^{25}$. Logo, temos o seguinte:

A Organização das Nações Unidas (ONU) definiu justiça transicional como o
conjunto de processos e mecanismos relacionados com os esforços de uma
sociedade para superar um legado de graves violações de direitos humanos
cometidos em larga escala no passado, a fim de assegurar responsabilização, a
administração da justiça e a reconciliação. [...] O objetivo central do processo de
justiça de transição é o fortalecimento do Estado democrático de direito, com o
desenvolvimento de garantias para que não se repitam violações em massa aos
direitos humanos. Para alcançar esses objetivos, foram concebidas diversas
estratégias judiciais e não-judiciais. Em geral, essas medidas se desenvolvem nos
campos da promoção da justiça, revelação da verdade, reparação das vítimas,
preservação e divulgação da memória e implementação de reformas institucionais. A
justiça de transição é um fenômeno jurídico e político com início nos anos noventa
do século XX, embora alguns autores reconheçam práticas transicionais desde a
antiga Grécia e outros considerem que os julgamentos de Nüremberg (pós-Segunda
Guerra Mundial) foram o estopim da política de justiça transicional.

No Brasil temos uma gama de complexidades históricas que fazem com que tal processo não esteja acabado. Isto claramente é um efeito do que já foi pontuado anteriormente no texto, ou seja, quando o Estado brasileiro agiu foi ineficaz (sem metodologia e conceitos bem definidos) e por isso pode ter cometido um anacronismo. Vejamos como ocorreu a justiça de transição no Brasil em apertada síntese:

No Brasil, a Constituição de 1988 é o marco normativo da transição. Com ela foram adotadas reformas institucionais e jurídicas que alteraram a conformação de instituições-chave para a democracia, especialmente o Ministério Público, e introduzidas a promoção e a proteção dos direitos humanos como elemento central do Estado. Ademais, os artigos $8^{\circ}$ e $9^{\circ}$, do Ato das Disposições Constitucionais Transitórias, estipularam a "anistia" aos cidadãos que haviam sido atingidos por atos de exceção em decorrência de motivação exclusivamente política, com a instituição de um regime específico de reparações. Apesar do primeiro passo dado pela Constituição, o País não desenvolveu uma política abrangente e efetiva de justiça transicional. [...] As principais iniciativas de justiça de transição implementadas pelo Governo ou aprovadas pelo Congresso Nacional foram: (a) a edição da Lei $n^{\circ}$ 9.140/1995, com a qual se reconheceram os mortos e desaparecidos políticos pela repressão, se garantiu às famílias o direito à reparação e à busca e identificação dos restos mortais e se instituiu a Comissão Especial sobre Mortos e Desaparecidos Políticos (CEMDP); (b) a promulgação da Lei $\mathrm{n}^{\circ} 10.559 / 2002$, a qual regulamentou o artigo $8^{\circ}$ das Disposições Transitórias da Constituição, criou a Comissão de Anistia e promoveu um amplo sistema de reparações materiais; (c) a instituição de uma Comissão Nacional da Verdade (CNV), com a Lei $n^{\circ} 12.528 / 2011$; e (d) a

\footnotetext{
${ }^{25}$ Como no site: http://www.justicadetransicao.mpf.mp.br/ em que estão disponíveis documentos, textos, e ações criminais ligadas ao tema.

26 MPF: Ministério Público Federal. Justiça de Transição. Disponível em: < http://www.justicadetransicao.mpf.mp.br/>. Acesso em: 20 de AGO. 2019.
} 
reforma do marco normativo sobre transparência e sigilo de arquivos, com a Lei $\mathrm{n}^{\circ}$ 12.527 , de $2011 .^{27}$

Não menos prejudicial do que essa lenta construção da justiça de transição no Brasil foi o julgamento pelo Supremo Tribunal Federal - STF da Arguição de Descumprimento de Preceito Fundamental 153 (ADPF 153):

EMENTA: Lei $\mathrm{n}^{\circ}$. 6.683/79, a chamada "Lei de Anistia". Art. 5. ', caput, III e XXXIII, da CF/1988; princípio democrático e princípio republicano: não violação. Circunstâncias históricas. Dignidade da pessoa humana e tirania dos valores. Interpretação do direito e distinção entre texto normativo e norma jurídica. Crimes conexos definidos pela Lei 6.683/79. Caráter bilateral da anistia, ampla e geral. Jurisprudência do STF na sucessão das frequentes anistias concedidas, no Brasil, desde a República. Interpretação do direito e leis-medida. Convenção das Nações Unidas contra a Tortura e outros Tratamentos ou Penas Cruéis, Desumanos ou Degradantes e Lei. 9.455, de 7 de abril de I997, que define o crime de tortura. Art. 5. “,XLIII, da CF/1988. Interpretação e revisão da Lei da Anistia. Emenda Constitucional n. 26, de 27 de novembro de 1985, poder constituinte e "autoanistia". Integração da anistia da lei de 1979 na nova ordem constitucional. Acesso a documentos históricos como forma de exercício do direito fundamental a verdade. ${ }^{28}$

Essa ADPF 153 foi proposta pela Ordem dos Advogados do Brasil e o Supremo Tribunal Federal decidiu por maioria de votos que a Lei de Anistia foi integrada pela Constituição de 1988 e que justamente por isso sua validade estava reafirmada.

Tal argumento é um anacronismo de proporções consideráveis, pois para compreendêlo basta recobrarmos que a Lei de Anistia foi fruto de um governo ilegítimo que chegará ao poder por meio de um golpe de estado em 1964, ou seja, a lei possui vício grave em sua essência. Para José Carlos Moreira da Silva Filho:

É bem verdade que, sob o ponto de vista jurídico, embebido nos princípios, direitos e garantias fundamentais da Constituição de 1988 e no Direito Internacional dos Direitos Humanos, a questão sobre se houve ou não um acordo por trás da anistia de 1979 é irrelevante, pois não deveria ser admissível qualquer acordo que buscasse passar por cima dos Direitos e Garantias Fundamentais. Segundo a Constituição de 1988, inclusive, nem mesmo uma Emenda Constitucional poderia fazer isso, quanto mais um acordo político elaborado no curso de um regime ditatorial. O mesmo entendimento pode ser depreendido de toda a legislação e jurisdição internacional voltada aos Direitos Humanos e aos quais não apenas o Brasil se filia e se submete, mas também abriga em seu texto constitucional ao incorporar outros direitos e garantias fundamentais firmados no plano internacional e não mencionados explicitamente na Constituição. De todo modo, entende-se importante e esclarecedor vislumbrar as mais do que equivocadas análises históricas feitas pelos magistrados da Suprema Corte brasileira, o que muito tem a dizer inclusive sobre o próprio papel histórico do Poder Judiciário brasileiro, tradicionalmente elitista e subserviente aos

\footnotetext{
${ }^{27}$ MPF, 2019, sp.

${ }^{28}$ STF: Supremo Tribunal Federal. Argüição de Descumprimento de Preceito Fundamental 153 - Distrito Federal. Relator Ministro Eros Roberto Grau. Disponível em: <http://www.stf.jus.br/arquivo/cms/noticiaNoticiaStf/anexo/ADPF153.pdf> Acesso em: 30 Mar. 2011.
} 
autoritarismos de diferentes matizes que foram se firmando ao longo da conturbada história política brasileira. ${ }^{29}$

O fragmento acima citado é irrepreensível, salvo quando diz que é irrelevante saber se ocorreu um pacto/acordo por detrás da anistia em 1979. Ao contrário do autor pensamos que a existência do dito pacto em torno da anistia em 1979 é fundamental para que possamos entender a situação brasileira na história, pois tal pacto, que depois seria reforçado pela Emenda Constitucional 26 de 27 de novembro de 1985, dá pistas de que o estado de exceção não terminou, logo é possível que a efetividade do conceito de justiça de transição no Brasil tenha soçobrado inócua, uma falácia.

Este é o ponto que faz com que o Brasil seja um caso sui generis para se discutir justiça de transição. Pois a transação em torno da Lei de Anistia de 1979 desvela seu caráter de perpetuação das estruturas de opressão atuantes na ditadura, ou seja, pode nunca ter ocorrido transição no Brasil.

Como indícios de que o período de exceção não ocorreu basta analisar a dificuldade, morosidade com que o processo se deu até a Criação da Comissão Nacional da Verdade, outro exemplo é o Julgamento da ADPF 153 pelo Supremo Tribunal Federal, e por fim o desmonte na Comissão Nacional da Verdade (dramaticamente construída) pelos governos do golpista de Michel Miguel Elias Temer Lulia e do fascista de Jair Messias Bolsonaro.

Portanto, não há como discutir tal tema no Brasil sem que se reflita em torno do estado de exceção. Segundo Giorgio Agamben "O estado de exceção fica no limite entre a política e o direito". ${ }^{30}$ Neste sentido este lugar encontra-se entre o mundo real representado pela política (ser) e o mundo virtual representado pelo direito (dever ser). Logo, o estado de exceção é a forma legal do que não pode ter forma legal. ${ }^{31}$

O estado de exceção volta-se para o espaço interno do Estado, para seus elementos constituidores povo, território e poder. E é o que se define como guerra civil legal e um exemplo seria o "Decreto para a proteção do povo e do Estado" de Adolf Hitler que suspendeu direitos relativos às liberdades

O decreto nunca foi revogado, de modo que todo o Terceiro Reich pode ser considerado, do ponto de vista jurídico, como um estado de exceção que durou doze anos. O totalitarismo moderno pode ser definido, nesse sentido, como a instauração,

\footnotetext{
${ }^{29}$ SILVA FILHO, José Carlos Moreira da. Justiça de transição: da ditadura civil-militar ao debate justransicional: direito a memória e à verdade e os caminhos da reparação e da anistia no Brasil. Porto Alegre: Livraria do Advogado Editora, 2015. p.91.

${ }^{30}$ AGAMBEN, Giorgio. Estado de exceção. Tradução de Iraci D. Poleti. São Paulo: Boitempo, 2004. p. 11.

${ }^{31}$ Ibidem, p. 12.
} 
por meio do estado de exceção, de uma guerra civil legal que permite a eliminação física não só dos adversários políticos, mas também de categorias inteiras de cidadãos que, por qualquer razão, pareçam não integráveis ao sistema político. Desde então, a criação voluntária de um estado de emergência permanente (ainda que, eventualmente, não declarado no sentido técnico) tornou-se uma das práticas essenciais dos Estados contemporâneos, inclusive dos chamados democráticos. Diante do incessante avanço do que foi definido como uma "guerra civil mundial", o estado de exceção tende cada vez mais a se apresentar como o paradigma de governo dominante na política contemporânea. Esse deslocamento de uma medida provisória e excepcional para uma técnica de governo ameaça transformar radicalmente - e, de fato, já transformou de modo muito perceptível - a estrutura e o sentido da distinção tradicional entre os diversos tipos de constituição. O estado de exceção apresenta-se nessa perspectiva, como um patamar de indeterminação entre democracia e absolutismo. ${ }^{32}$

Trazendo a análise do estado de exceção para o plano mais específico do Brasil temos a contribuição do professor Florestan Fernandes que analisou o fato de que a burguesia nacional diretamente se relaciona com o estado de exceção, ou seja, ela fomenta de modo direto a suspensão dos direitos da população para manter-se em seu posto de privilégio.

$\mathrm{Na}$ mesma linha cite-se o seguinte fragmento para corroborar com a compreensão desse raciocínio, pois "nossa burguesia" se moldou patrimonialista, escravista, e atuou ao longo da história sempre fundada na repressão das massas, às vezes mais repressão, e às vezes menos repressão.

No fundo, a referida reviravolta confere novos fundamentos psicológicos, morais e
políticos ao enrijecimento da dominação burguesa e à sua transfiguração numa força
social especificamente autoritária e totalitária. É aqui, e não numa suposta
deterioraçãa do liberalismo nem numa presumível exacerbação do mandonismo
tradicionalista, que se devem procurar as raízes psicossociais e históricas da
mudança do horizonte cultural das classes e estratos de classes burgueses. Essa
mudança levou, gradualmente, nas últimas quatro décadas, a uma nova filosofia
política e a ações de classes que puseram em primeiro plano o privilegiamento as
situação de interesses da burguesia como um todo. Ela serviu, pois como de
fundamento para uma solidariedade de classes que deixou de ser 'democrática' ou,
mesmo, 'autoritária', para tornar-se abertamente 'totalitária' e contra-revolucionária,
em suma, o fermento de uma ditadura de classe preventiva. ${ }^{33}$

Esse é o aspecto específico do estado de exceção brasileiro, ou seja, a regra da suspensão dos direitos está diretamente ligada aos interesses da burguesia nacional que temerosa em perder seu posto de privilégio dentro da estrutura gerida pelo Estado trabalhará para que exista uma situação contra-revolucionária inicialmente preventiva, mas que se tornou permanente, e isto é justamente o que Giorgio Agamben definiu como o espaço entre a política e o direito, ou seja, o próprio estado de exceção.

\footnotetext{
${ }^{32}$ AGAMBEN, 2004. p. 12/13.

${ }^{33}$ FERNANDES, Florestan. A revolução burguesa no Brasil; ensaio de interpretação sociológica. 3 ed. Rio de Janeiro: Guanabara, 1987. p. 317.
} 
Comprovação disso é o papel de suporte que o empresariado deu ao regime ditatorial brasileiro. Ocorre que isso é constante ao longo da história brasileira, e por isso é possível extrair do pensamento de Giorgio Agamben e Florestan Fernandes que no Brasil sempre esteve vigente o estado de suspensão dos direitos.

$\mathrm{O}$ dito estado de exceção do Brasil às vezes foi mais claro, outras vezes velado, mas sempre se tivemos o estado de exceção como regra, ou seja, constante em nossa história. Exemplos: genocídio indígena, destruição do Quilombo dos Palmares, A Guerra de Canudos, a ditadura do estado novo, a ditadura militar, massacre do Carandiru, a onda do lavajatismo, os massacres recentes nos presídios de Manaus-AM, etc.

A nossa história é fundada na mais brutal violência contra a população despossuída, ou seja, nunca superamos o período de suspensão dos direitos, o estado de exceção no Brasil é uma regra. Neste sentido, é o Brasil só tem um tempo histórico que é a suspensão dos direitos, o estado de exceção, ou a contrarrevolução preventiva e prolongada. Isso reflete em nossa incapacidade de promover a justiça de transição, pois o autoritarismo ainda é tempo presente.

Feitas essas ponderações, bem verdade que em apertada reflexão dado o objetivo do presente texto e os limites formais, não poderíamos de refletir sobre a nossa história para responder a uma indagação fundamental: a história deve ser julgada ou compreendida?

Julgar ou compreender? A fórmula do velho Ranke é célebre: o historiador propõe
apenas descrever as coisas "tais como aconteceram, wie es eigentlich geweserí'.
Heródoto o dissera antes dele, "ta eonta legein, contar o que foi". O cientista, em
outros termos, é convidado a se ofuscar diante dos fatos. Como muitas máximas,
esta talvez deva sua fortuna apenas à sua ambiguidade. Podemos ler aí,
modestamente, um conselho de probidade: este era, não se pode duvidar, o sentido
de Ranke. Mas também um conselho de passividade. De modo que eis, colocados de
chofre, dois problemas: o da imparcialidade histórica; o da história como tentativa
de reprodução ou como tentativa de análise. ${ }^{34}$

Sem temor de ser definido como repetitivo, mas mais preocupado em pontuar o prisma com que se analisa o objeto, destacamos que apesar de formação em área diversa é fundamental para o trabalho estarmos na posição não de historiador, mas de observador da história, um observador que utiliza das ferramentas proporcionadas pelo direito.

Portanto, eventuais fendas na condução do raciocínio devem ser entendidas como decorrentes da utilização de instrumentos estranhos, ou diferentes, dos mais adequados, entendidos estes como os normalmente utilizados pelo historiador.

\footnotetext{
${ }^{34}$ BLOCH, Marc. Apologia da História ou O Ofício de Historiador. Edição anotada por Étienne Bloch. Prefácio: Jacques Le Goff. Apresentação à edição brasileira: Lilia Moritz Schwarcz Tradução: André Telles. Jorge Zahar Editor Ltda: Rio de Janeiro. 2002. p. 125.
} 
Logo, quando se fala em justiça de transição é preciso entender que não se trata meramente de atuação via poder Judiciário, apesar de que é provável que alguma(s) vez(es) tenha sido feita justiça mediante atuação do Judiciário. A discussão em torno da justiça de transição é ampla e extrapola o judiciário e neste sentido é ela trabalha necessariamente com um processo mais voltado para o julgamento da história.

Mas quando se fala em julgamento da história é importante que se tome ao menos três precauções: $1^{a}$ ) Não há como julgar sem que se tenha a compreensão da história. $2^{a}$ ) Julgar não pode ser confundido com a ação do juiz de carreira ou com a emissão de juízo de valor fundado em senso comum. $3^{\text {a }}$ ) Não se pode julgar um fato que não esteja no passado.

O processo de julgar a que nos referimos equivale a uma reflexão profunda e filosófica que permita ao homem regressar e se posicionar no mesmo tempo e espaço do fato que se quer julgar. Realizar tal processo/exercício sem a adoção das precauções adequadas cometerse-ão anacronismos como o julgamento da ADPF 153 pelo Supremo Tribunal Federal por exemplo.

Porém, o anacronismo é importante na medida em que serve como uma espécie de medidor, um indicativo, do nível de eficácia, ou efetividade, da justiça de transição. Equivale a sabermos se o regresso do direito no tempo foi exitoso ou não, e no caso brasileiro, sobretudo no julgamento da $\mathrm{ADPF}$ 153, não obtivemos êxito, porém ainda é uma tarefa possível.

\section{Considerações Finais.}

Ao longo do texto deixamos claro o fato de que apesar de não possuir formação específica em história não deixaríamos de correr os riscos de realizar uma análise de como a justiça de transição é relaciona-se com o poder, tempo e história. Bem verdade que essa analise foi da perspectiva mais de um filósofo que observa a história do que de um historiador propriamente dito.

E esta forma de abordagem permitiu uma segurança para que adentrássemos no campo tão complexo como é a história. Neste sentido, ressaltamos a importância de apoiarmo-nos em conceitos e conhecimentos de autores como Santo Agostinho e Stephen William Hawking que nos possibilitaram o pensamento central do presente artigo, que é a possibilidade que o direito, entendido como ideia, possui de realizar o regresso ao passado. 
Dessa forma, o instrumento que possibilita materialmente esse regresso do direito ao passado é a justiça de transição. Porém, para tanto é fundamental que a situação de autoritarismo, ou o período de suspensão dos direitos, ou ainda o estado de exceção, já esteja no passado. Ocorre, que no Brasil demonstramos que a suspensão dos direitos é constante, ou seja, ainda é tempo presente e isso inviabiliza a justiça de transição.

Daí o motivo pelo qual no Brasil o desenvolvimento da estrutura estatal voltada para a justiça de transição tenha se dado de modo lento, modesto, e principalmente proporcionando anacronismos como no caso do julgamento da ADPF 153 pelo Supremo Tribunal Federal que propunha a revisão da Lei de Anistia $\mathrm{n}^{\circ}$. 6.683/79, pois a suprema corte ratificou a validade de tal lei ao arrepio de todo ordenamento internacional sobre crimes contra a humanidade.

A justiça de transição é o instrumento que se adequadamente utilizado permitirá que o direito regresse no tempo e espaço para que se corrijam os fatos que potencializam a desordem ou entropia (conforme definiu Stephen William Hawking) tendo em vista que caminhamos para a desordem/entropia no futuro, mas que podemos retardar se o soubermos utiliza-la.

Portanto, ao utilizar a justiça de transição de modo capaz de atingir tal objetivo precisa primeiramente compreender a história; posteriormente julgá-la sem confundir isso com a atuação de um juiz de carreira e muito menos com a emissão de decisão com base no senso comum; e por fim que o fato que se quer julgar esteja no passado e não no presente.

Porém, no Brasil constatamos que só existe um tempo histórico: $\mathrm{O}$ da suspensão dos direitos, ou estado de exceção de Giorgio Agamben, ou ainda a contrarrevolução preventiva e prolongada de Florestan Fernandes. Isso reflete em nossa incapacidade de promover a justiça de transição, pois o autoritarismo ainda é tempo presente no Brasil.

Apesar de as pesquisas ainda não terem sido concluídas essas constatações prévias já nos surgiram e, portanto entendemos importante o compartilhamento de tais ideias.

\section{Referências.}

ABBAGNANO, Nicola. Dicionário de filosofia. Tradução Alfredo Bosi. 2 ed. São Paulo: Martins Fontes, 1998.

ABRÃO, Paulo. PAYNE, Leigh A. TORELly, Marcelo D. A anistia na era da responsabilização: $O$ Brasil em perspectiva internacional e comparada. Brasília: 
Ministério da Justiça, Comissão de Anistia: Oxford: Oxford University, Latin American Centre, 2011.

AGAMBEN, Giorgio. Estado de exceção. Tradução de Iraci D. Poleti. São Paulo: Boitempo, 2004.

AGÊNCIA BRASIL. Alemanha vai julgar ex-guarda nazista por 5.230 mortes. Disponível em: <https://www.msn.com/pt-br/noticias/mundo/alemanha-vai-julgar-ex-guarda-nazista-por5230-mortes/ar-AAFK9Bh?li=AAggXC1\&ocid=mailsignout $>$. Acesso em: 14 de AGO. 2019.

BLOCH, Marc. Apologia da História ou O Ofício de Historiador. Edição anotada por Étienne Bloch. Prefácio: Jacques Le Goff. Apresentação à edição brasileira: Lilia Moritz Schwarcz Tradução: André Telles. Jorge Zahar Editor Ltda: Rio de Janeiro. 2002.

DINIZ, Carlos Augusto de Oliveira. Estado, poder e fetichismo: comunicação e mensuração do poder. Tese de Doutorado em Direito - Pontifícia Universidade Católica de São Paulo (PUC/SP). 2016. 163 p.

FERRAZ JUNIOR, Tercio Sampaio. Estudos de filosofia do direito: reflexões sobre o poder, a liberdade, a justiça e o direito. 3 ed. São Paulo: Atlas, 2009.

FOUCAULT, Michel. Microfísica do Poder. Organização, Introdução e revisão técnica de Roberto Machado. 25 a ed. São Paulo: Graal, 2012.

GONÇALVES, Danyelle Nelin. O preço do passado: anistia e reparações de perseguidos políticos no Brasil. 1 ed. São Paulo: Expressão Popular, 2009.

HAWKING, Stephen William. Uma breve história do tempo. Ilustração Ron Miller; Tradução Cássio de Arantes Leite. 1 ed. Rio de Janeiro: Intrínseca, 2015.

JORNAL GGN. Pela $1^{\text {a }}$ vez, Justiça entende que tortura não prescreve e transforma agente da Ditadura em réu. Disponível em: <https://jornalggn.com.br/noticia/pela-1a-vezjustica-entende-que-tortura-nao-prescreve-e-transforma-agente-da-ditadura-em-reu/>. Acesso em: 15 de AGO. 2019.

LE GOFF, Jacques. História e memória / Jacques Le Goff; tradução Bernardo Leitão. [et al.]. Campinas: Editora da UNICAMP, 1990.

MPF: Ministério Público Federal. Justiça de Transição. Disponível em: < http://www.justicadetransicao.mpf.mp.br/>. Acesso em: 20 de AGO. 2019.

SILVA FILHO, José Carlos Moreira da. Justiça de transição: da ditadura civil-militar ao debate justransicional: direito a memória e à verdade e os caminhos da reparação e da anistia no Brasil. Porto Alegre: Livraria do Advogado Editora, 2015.

SOUSA JUNIOR, José Geraldo de. O direito achado na rua: introdução crítica à justiça de transição na América Latina / José Geraldo de Sousa Junior, José Carlos Moreira da 
Silva Filho, Cristiano Paixão, Lívia Gimenes Dias da Fonseca, Talita Tatiana Dias Rampin. 1. ed. - Brasília, DF: UnB, 2015.

STF: Supremo Tribunal Federal. Argüição de Descumprimento de Preceito Fundamental 153 - Distrito Federal. Relator Ministro Eros Roberto Grau. Disponível em: <http://www.stf.jus.br/arquivo/cms/noticiaNoticiaStf/anexo/ADPF153.pdf> Acesso em: 30 Mar. 2011. 